\title{
Influence of change in frictional condition of track rail surfaces on interaction forces in the "wheel/rail" contact
}

\author{
Inna Parakhnenko ${ }^{1, *}$, Sergey Akkerman ${ }^{1}$, Andrey Romanov ${ }^{2}$, and Oksana Shalamova ${ }^{3}$ \\ ${ }^{1}$ Ural State University of Railway Transport 64 Kolmogorov St., 620034 Yekaterinburg, Russia \\ ${ }^{2}$ Emperor Alexander I St. Petersburg State Transport University 9 Moskovsky pr., 190031 St. \\ Petersburg, North-Western Federal District, Russia \\ ${ }^{3}$ Siberian Transport University 191 Dusya Kovalchuk St., 630049 Novosibirsk, Russia
}

\begin{abstract}
Determination of frictional condition of the running surface and side surface of the top of rail (lubrication) that ensures the best interaction of the rolling stock wheels and the rail, reduces the force action and thus ensures the track stability and reduced side wear of rails in the curved tracks is relevant for all the rail net.The objective of research is to determine the influence of frictional condition of the track rail surfaces on the interaction forces in the "wheel/rail" contact with various motion parameters (speed, radius).The theoretical and experimental methods were used in the research. The theoretical methods include multioptional computer modelling of axial and lateral forces that appear in the curved tracks during the freight train movement in the software package "Universal Mechanism". The modelling results were processed with the use of correlation and regression analysis. The experimental methods include full-scale measurements in the existing track and results processing.According to the research results, the theoretical algorithms for assessment of influence of the running surface lubrication on the forces. The option of frictional condition of the wheel and rail interaction surfaces has been established to ensure reduction in the operating expenses for surfacing and rail replacement, energy costs for haulage of freight train.
\end{abstract}

\section{Introduction}

The length of the railways of the Russian Federation makes $85,000 \mathrm{~km}, 33 \%$ of them are the curved tracks, the third part of which has the radii from 400 to $700 \mathrm{~m}$. When a train passes the curved tracks, especially those of small radius, frictional resistance appears that influences the energy consumption and impairs the track geometry stability, intense wear of wheels and rails. These problems are caused by dynamic forces (axial and lateral) appearing in the "wheel/rail" contact zone [1].

Change in the frictional condition of the track rail surfaces, that is reduced friction coefficient in the wheel/rail contact zone (lubrication), is one of the main measure included

\footnotetext{
* Corresponding author: Iparahnenko@usurt.ru
} 
in the complex resource saving program "2030 Russian Railways Development Plan" aimed at reducing two-body wear [2].

The scientific area in research of the rolling stock and curved track interaction remains relevant during the entire railway operation period. The fundamentals of the theory of motion and guiding of vehicle in curves have been determined and formulated, the forces determining the track stability have been identified. The Russian scientists (Railway Research Institute) actively collect the statistical data and analyse the train movement in the curved tracks. They develop and implement the methods to determine the dynamic lateral forces in the random and curved tracks $[3,4,5]$. The foreign scientists (USA) point out the necessity of quantitative assessment of the "wheel/rail" operation, especially in the curved tracks. Focusing on such values as an angle of attack, the lateral and axial forces appear in the contact zone [6]. However, the analysis of the conducted researches showed that the numerical values of the friction coefficients on the lateral surface and track running surfaces (frictional condition) and their influence on the wheel/rail force interaction in the curved tracks have been insufficiently considered [7,8].

The objective of the research is to determine frictional condition of the running surface and side surface of the top of rail (lubrication) to ensure the best interaction of the rolling stock wheels and the rail, reduces the force action and thus ensures the track stability and reduced side wear of rails in the curved tracks is relevant for all the rail net.

\section{Materials and methods}

The friction appearing in the contact zone during the rolling stock wheels running on the track rails plays a key role in the interaction. Stage I of the research set forth the goal consisting in measurement of the friction coefficients on the track rail surfaces of the operating railway section. The portable rail tribometer developed by the Research and Design and Technological Institute of Rolling Stock (VNIKTI) [9] with MIC-212 module by SPC "Mera" as shown in Figure 1 was used as a tool for the friction force measurement and then for the friction coefficient calculation.

a

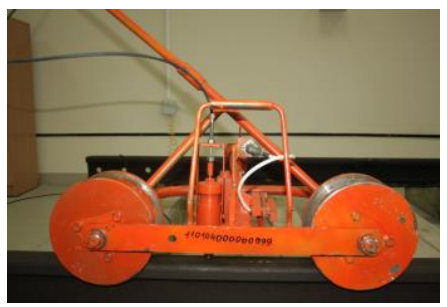

b

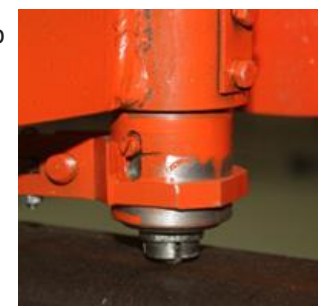

c

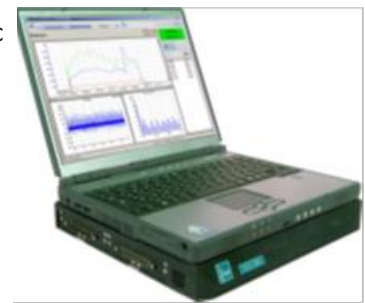

Fig. 1. Portable rail tribometer by VNIKTI

$\mathrm{a}-$ general view of tribometer, $\mathrm{b}$ - working head for friction coefficient measurement, $\mathrm{c}$ - computer data record module

A circular curve with $\mathrm{l}=290 \mathrm{~m}, \mathrm{R}=540 \mathrm{~m}$, and vertical setting of rail $\mathrm{h}=64 \mathrm{~mm}$ was taken as an object.

Yekarinburg-Kamensk-Uralsk section (Koltsovo-Lechebny running line) Working capacity is $96.66 \mathrm{mln}$. gross, freight train speed is $40 \mathrm{~km} / \mathrm{h}$.

The friction force was measured according to the reading sequence method developed by the Railway Research Institute:

1. Tribometer reading in the gauge face before lubrication $(2 \div 3$ times $)$.

2. Rail lubricator passing.

3. Tribometer reading in the gauge face after the rail lubricator passing ( $2 \div 3$ times).

4. Tribometer reading in the gauge face after the railway train passing ( $2 \div 3$ times), calculation of the number of wheel sets in each railway train. 
5. The friction coefficient is measured before the rail lubricator passing.

6. Obtained data processing and analysis.

The experiment was conducted twice in the different weather conditions (in August in dry and warm weather and in September at the decreasing temperatures and increasing precipitations) [10]. The measurements were taken on the lateral surface of the exterior rail and on the running surfaces of the both track rails. The immediate indications, depending on the distance passed (length of the curve), are shown in oscillograms, Figure 2.

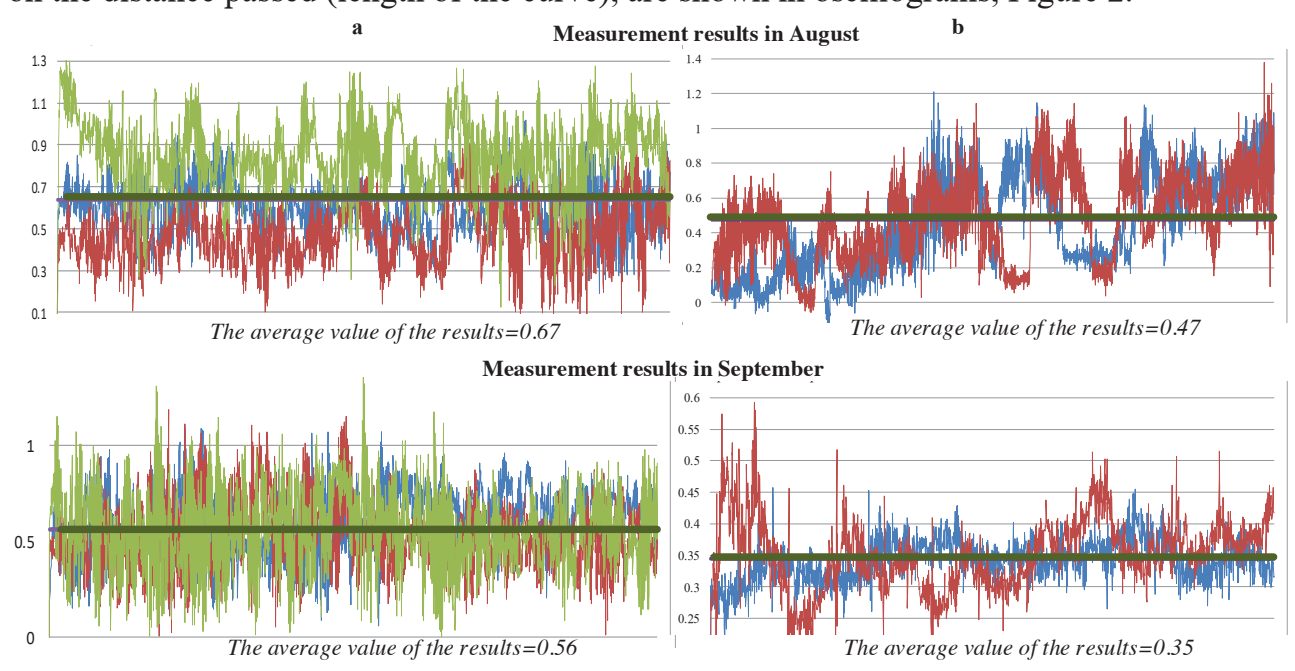

Fig. 2. Friction coefficient oscillograms

$\mathrm{a}-$ measurement of friction coefficient on the running surfaces of the track rails.

$\mathrm{b}$ - measurement of friction coefficient on the lateral surface of the exterior rail

Based on the experiment results, the following conclusions have been made:

- the friction coefficient on the lateral surface of the rail in dry (without lubrication) frictional condition according to several measurements is 0.415 ;

- on the running surface -0.58 .

In the framework of the full-scale measurement according to the method mentioned above, the friction coefficient was measured on the lateral surface of the exterior rail with lubrication used. The friction coefficient was observed and measured till lubrication exhaustion within 24 hours. The freight trains of various weight and length (average load $20.5 \mathrm{t}$ per axle), passenger and local trains were allowed to pass this section. The summary results are given in the form of diagram in Figure 3. 

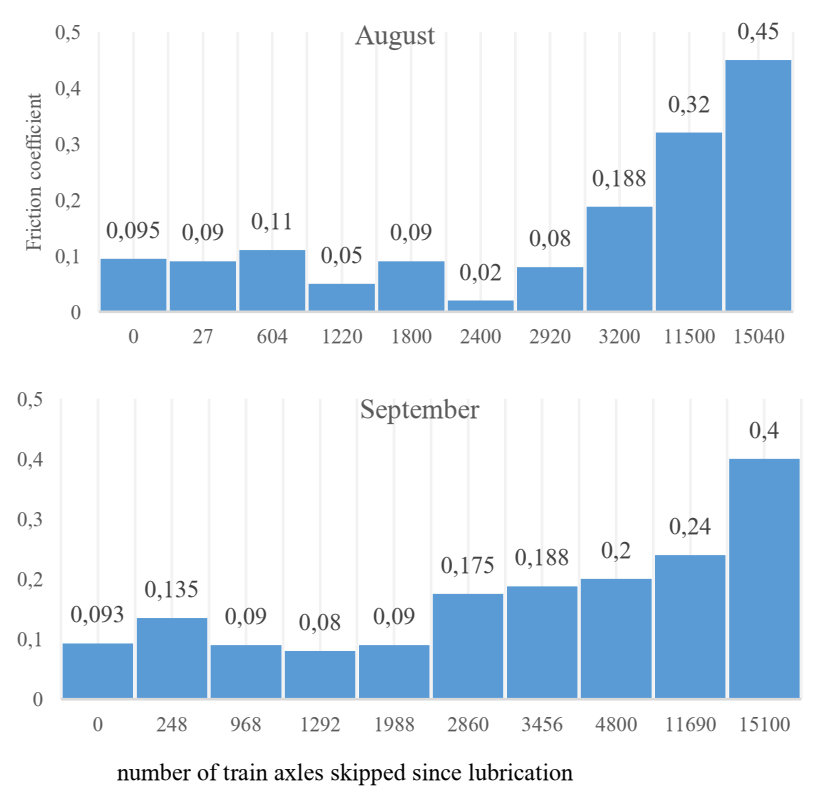

Fig. 3. Friction coefficient measurement results with lubrication used

By analysing the obtained data, it can be concluded:

- that from lubrication in the contact zone till material exhaustion in the section under review, 15,000 train axles passed and the friction coefficient achieved the value being equal to the dry frictional conditions (without lubrication).

- with lubricant applied to the lateral surface of the exterior rail, the maximum number of the skipped train axles was observed with the friction coefficient varying within 0.2 and 0.3 .

Based on the values obtained, the following friction coefficients were taken for further research: with lubricant present in the contact zone -0.25 , and for dry condition of track rails (without lubrication) - 0.4 .

Stage II of researches is based on modelling the wheel and track interaction in the software package "Universal Mechanism" that serves for modelling the dynamics and kinematics of the flat and spatial mechanical systems on the basis of absolutely solids connected by random kinematic pairs and force members [11,12]. Verification of this software package is confirmed by Manchester tests [13]. Studying the force interaction of the rolling stock in curves is provided by the mathematical freight car 3D model with a separate procedure included in the structure. The feature allowing to specify straight and curved lines is implemented in the software module "Modelling of vehicle and track interaction" with various frictional options of contacting wheel and rail surfaces.

The model of freight train that is maximally close to the real one consisting of 2 traction modules $\left(\mathrm{OHL} 80^{\circ}\right)$ and 62 solid metal freight cars with bogie TSNII 18-100, with axle load of $23.5 \mathrm{t}$ and included three $3 \mathrm{D}$ cars, has been created in the software package. The total length of the rolling stock has made $968 \mathrm{~m}$, the total weight $-6,494 \mathrm{t}$. The simulation was performed for the track section where the experiment was conducted. The reviewed train speeds were 40, 50, 60 and $80 \mathrm{kn} / \mathrm{h}[14]$. 
Table 1. Characteristics of the reviewed section

\begin{tabular}{|c|c|}
\hline $\begin{array}{c}\text { Longitudinal profile elements } \\
\text { (R-radius, } 1_{1} \text {-inlet curve length, } 1 \text {-constant-radius curve length, } 1_{2} \text {-outlet curve } \\
\text { length, } h \text {-height) }\end{array}$ & $\begin{array}{c}\text { Length of } \\
\text { the element, } \\
\mathrm{m}\end{array}$ \\
\hline Straight between two curves & 91.0 \\
\hline Circular curve (left): $\mathrm{R}=990 \mathrm{~m}, \mathrm{l}_{1}=110 \mathrm{~m}, \mathrm{l}=285 \mathrm{~m}, \mathrm{l}_{2}=100 \mathrm{~m}, \mathrm{~h}=35 \mathrm{~mm}$ & 495.0 \\
\hline Straight between two curves & 372.0 \\
\hline Circular curve (left): $\mathrm{R}=630 \mathrm{~m}, 1_{1,2}=80 \mathrm{~m}, \mathrm{l}=281 \mathrm{~m}, \mathrm{~h}=85 \mathrm{~mm}$ & 444.0 \\
\hline Straight between two curves & 94.0 \\
\hline Circular curve (right): $\mathrm{R}=540 \mathrm{~m}, \mathrm{l}_{1,2}=100 \mathrm{~m}, \mathrm{l}=79 \mathrm{~m}, \mathrm{~h}=100 \mathrm{~mm}$ & 279.0 \\
\hline Straight between two curves & 421.0 \\
\hline Circular curve (right): $\mathrm{R}=380 \mathrm{~m}, \mathrm{l}_{1}=110 \mathrm{~m}, \mathrm{l}=148 \mathrm{~m}, \mathrm{l}_{2}=70 \mathrm{~m}, \mathrm{~h}=70 \mathrm{~mm}$ & 328.0 \\
\hline Straight between two curves, $\mathrm{m}$ & $1,076.0$ \\
\hline Total length & 3,600 \\
\hline
\end{tabular}

On the basis of the experimentally obtained friction coefficients, possible options of frictional conditions of the track running surface was developed [15]:

1. dry track rails (without lubrication) $f m p=0.4$;

2. lubrication of the lateral surface of the exterior rail $f m p=0.25$ (classic method);

3. lubrication of the running surface of the exterior rail $f m p=0.25$;

4. lubrication of the running surface of the interior rail $f m p=0.25$;

5. lubrication of the running surface of both track rails $f m p=0.25$.

For modelling the wheel/rail interaction forces in the software package "Universal Mechanism", the sequence of modelling and results processing has been developed as given in Figure 4.

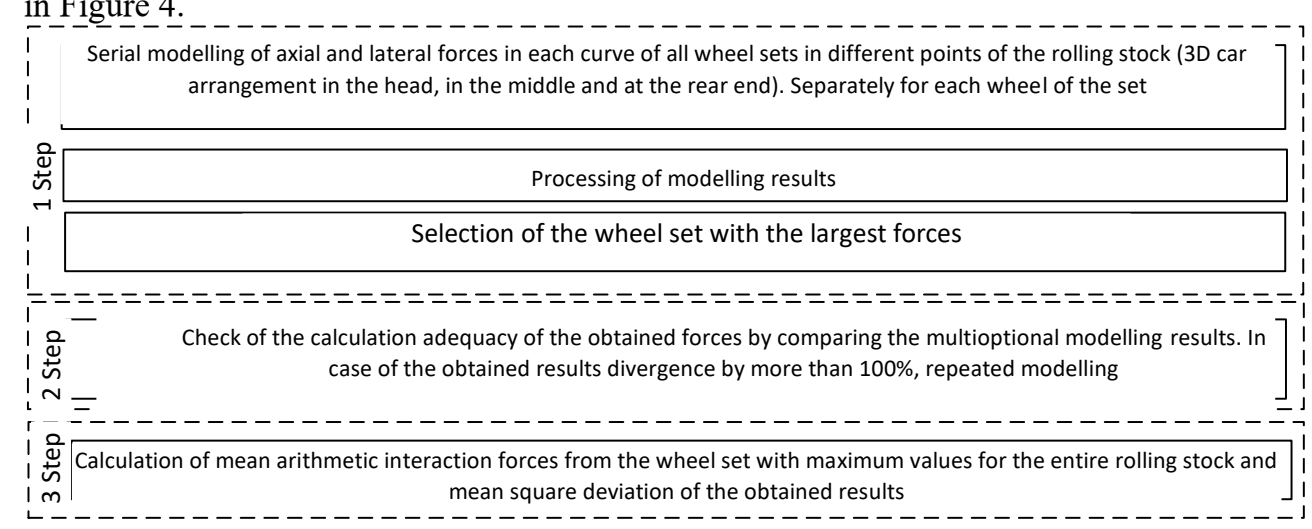

Fig. 4. Developed sequence of interaction forces modelling and obtained results processing

The performed simulation of the wheel/rail interaction forces found out that maximum axial and lateral forces appeared in the first wheel set of the freight car. For further research, the mean arithmetic forces obtained from the right and the left wheel of each wheel set and values obtained from 3D car arrangement in sequence in different parts of train for each curve of the accepted section have been calculated.

At stage III, the non-linear regression dependences between axial $\mathrm{Fa}$ and lateral Fl forces, curve radii $\mathrm{R}$, as well as options of frictional condition at different speeds have been identified on the basis of multioptional modelling results. The power regression equation for variables is generally as follows:

$$
F_{\text {п/б }}=a_{0} R^{a_{1}}
$$


The coefficients $\mathrm{a}_{0}$ and $\mathrm{a}_{1}$ are determined by set of equations:

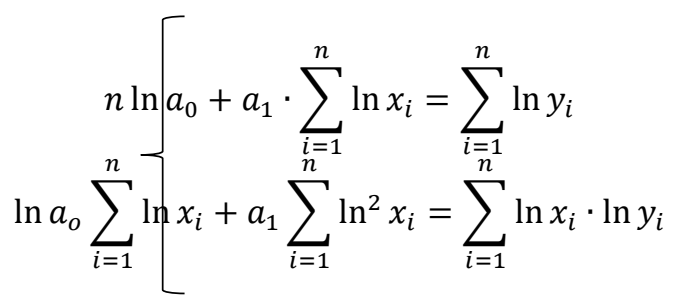

\section{Results}

The dependences of changes in axial and lateral forces received after processing of the modelling results for the reviewed frictional conditions of track rails on radius and motion speed of the rolling stock are shown in Figures 5 and 6.
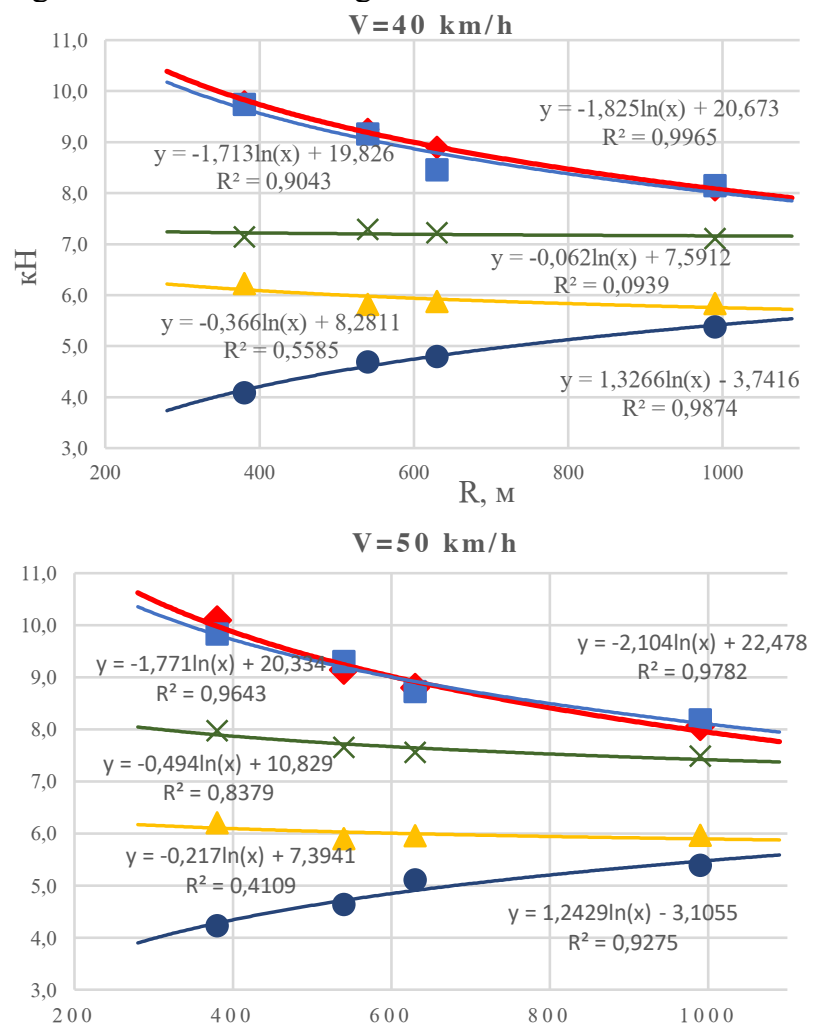

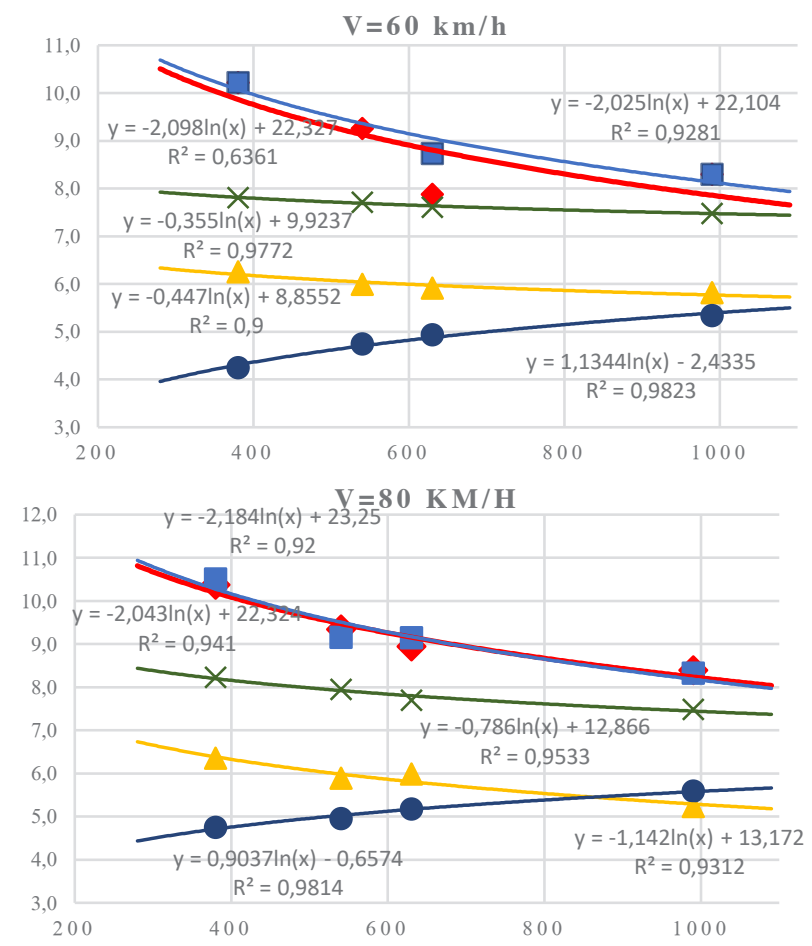

Fig. 5. Dependences of axial forces on curve radius with frictional conditions of track rails

- 1. dry track rails (without lubrication) $f m p=0.4$;

2. lubrication of the lateral surface of the exterior rail $f m p=0.25$ (classic method);

lubrication of the running surface of the interior rail fmp $=0.25$;

5. lubrication of the running surface of both track rails $f m p=0.25$. 

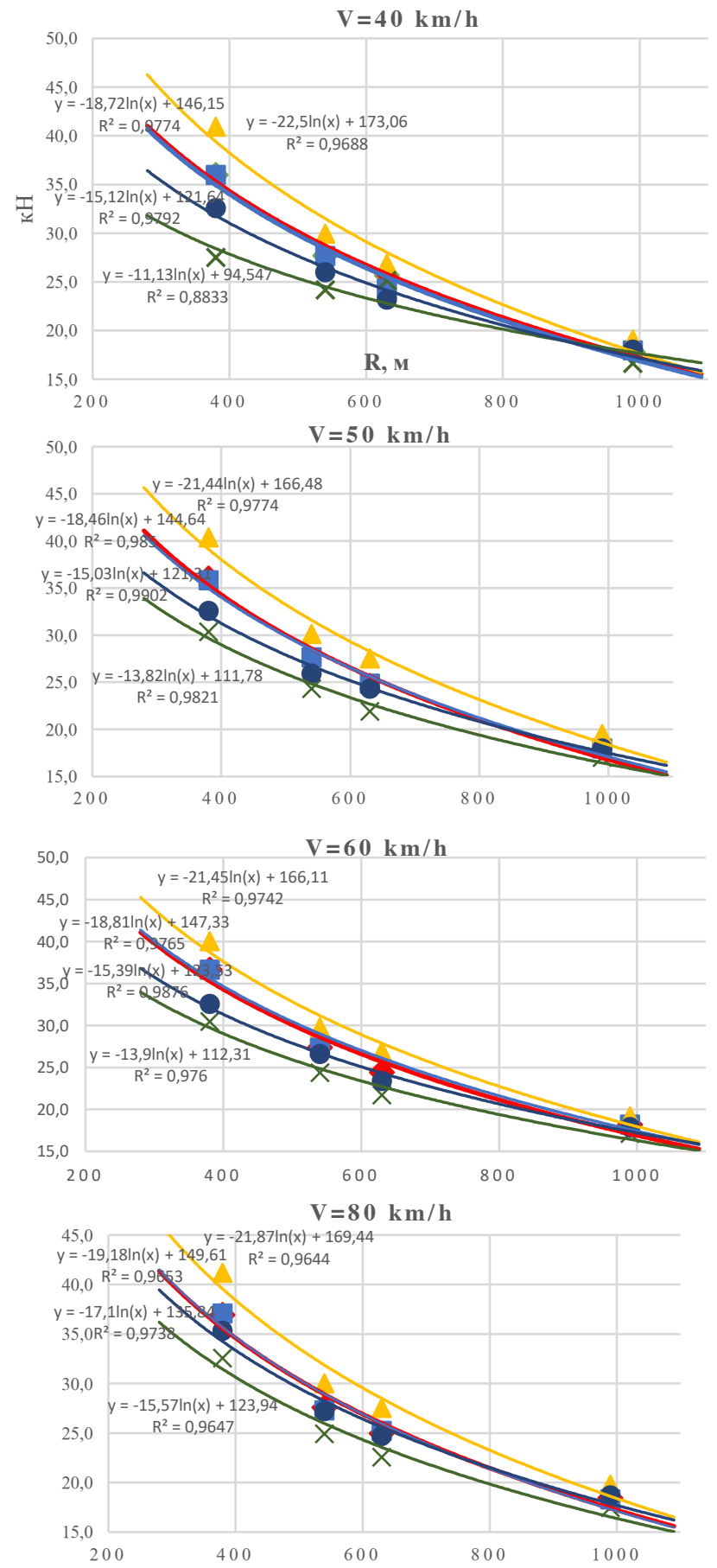

Fig. 6. Dependences of lateral forces on curve radius with frictional conditions of track rails

- 1. dry track rails (without lubrication) $f m p=0.4$;

- 2. lubrication of the lateral surface of the exterior rail $f m p=0.25$ (classic 4. method);

- 3. lubrication of the running surface of the exterior rail $f m p=0.25$; 
4. lubrication of the running surface of the interior rail $f m p=0.25$;

5. lubrication of the running surface of both track rails $f m p=0.25$.

\section{Discussion / Results Analysis}

To compare the obtained results and assess the efficiency (reduced power interaction), the researches with modelling for reference options, i.e. dry rail surface, and existing method, i.e. lubrication of the lateral surface of the exterior rail, have been conducted. By analysing the graphs of dependences of axial forces shown in Figure 5, the following can be stated:

Option 1 - as the speed increases, the axial forces increase by $10 \%$ in average. Maximum values are observed in small-radius curves.

Option 2 - as the motion speed of the vehicle changes, the forces change by $2 \%$ downwards relative to dry condition.

Option 3 - maximum efficiency, i.e. maximum decreases of forces relative to the dry frictional condition of track rails, reaches $39 \%$ in the curve $\mathrm{R}=380 \mathrm{~m}$ and $28 \%$ in the curve $\mathrm{R}=990 \mathrm{~m}$.

Option 4 - decreased action of forces from 21 to $27 \%$ is observed in the curve $\mathrm{R}=380 \mathrm{~m}$, the efficiency decreases as the speed increases. In the curves $540<\mathrm{R}<630 \mathrm{~m}$, the axial forces decrease by $14-19 \%$ depending on the motion speed (the higher the speed, the lower the efficiency). In the curve with the radius of $990 \mathrm{~m}$, the maximum efficiency makes $8 \%$ at all speeds.

Option 7 - efficient decrease of axial forces is achieved in small-radius curves up to $58 \%$ at speeds from 40 to $60 \mathrm{~km} / \mathrm{h}$. In the mid-radius curves, the forces decrease to $49 \%$. At $\mathrm{R}>900 \mathrm{~m}$, the maximum efficiency makes $33 \%$ that is obtained for the freight train speed of $80 \mathrm{~km} / \mathrm{h}$.

The analysis of graphs of lateral forces (Figure 6) allows to show that:

Option 1 - the increased speed influence the redistribution of lateral forces from the interior rail to the exterior rail. This is due to the increased centrifugal force. The mean value of the lateral force does not considerably change, and the curve characteristics $(R, h$, 1) remain unchanged.

Option 2 - the results obtained from modelling are very close to the values of lateral forces in dry condition of track rails, the difference makes no more than $2 \%$.

Option 3 - the lubrication efficiency on the running track of the exterior rail is negative for all considered radii and speeds that evidences the increase of lateral forces relative to dry frictional condition. The most significant increase of forces is observed in curves with the radius less than $600 \mathrm{~m}$.

Option 4 - efficient decrease to $23 \%$ is observed at $40 \mathrm{~km} / \mathrm{h}$ in small-radius curve, as the speed increases, the efficiency decreases to $12 \%$. In curves with the radius up to $700 \mathrm{~m}$, the lateral forces decrease by $17 \%$ at minimum speed, as the sped increases, the efficiency decreases to $10 \%$. With the radii more than $700 \mathrm{~m}$, the efficient decrease of action of lateral forces makes in average 5\% at all speeds.

Option 6 - the efficiency of less than $5 \%$ is observed in the curves $\mathrm{R}>540 \mathrm{~m}$ at all speeds of the rolling stock. The same result is in the curve $\mathrm{R}<540$ at $80 \mathrm{~km} / \mathrm{h}$. The maximum decrease in forces to $11 \%$ is achieved in the curve $\mathrm{R}=380 \mathrm{~m}$ at speeds up to $60 \mathrm{~km} / \mathrm{h}$.

\section{Conclusion}

Therefore, the conducted research made it possible to conclude the following:

The axial forces appearing in the wheel and rail contact decrease as the friction coefficient on the running surfaces of the both track rails decreases (Option 5) in small- 
radius curves to $58 \%$ (by $5.7 \mathrm{kN}$ ) relative to dry condition and in flat curves to $33 \%$ (by 2.7 $\mathrm{kN}$ ) at $80 \mathrm{~km} / \mathrm{h}$. Use of lubrication on the surface of one of track rails decreases the axial forces in the curve $\mathrm{R}=380 \mathrm{~m}$ to $39 \%$ (by $3.6 \mathrm{kN}$ ) when the exterior rail is lubricated (Option 3 ) and to $27 \%$ (by $1.9 \mathrm{kN}$ ) when the interior rail is lubricated (Option 4).

The lateral forces decrease to $23 \%$ (by $8.5 \mathrm{kN}$ ) when the friction coefficient on the running surface of the interior track rail decreases (Option 4). The lubrication of the running surfaces of both rails is efficient only in the curves $\mathrm{R}<500$ and at the speed up to 60 $\mathrm{km} / \mathrm{h}$. The lubrication was not found to be rational for decreasing the lateral forces in the curves $\mathrm{R}>900 \mathrm{~m}$, as the obtained results have close values in all options reviewed.

Based on the obtained results, the frictional condition of the rail surface, that decreases the axial and lateral forces in the wheel/rail contact zone that appear when the freight train is passing the curved tracks, is the lubrication of the running surface of the interior track rail. It is recommended to use this method for excessive gradients in the curves with the radius up to $1,200 \mathrm{~m}$ to reduce intensity of the corrugated and side rail wear, increase the track stability in plan and in profile, as well as reduce costs for haulage of trains [16] and infrastructure maintenance.

\section{References}

1. Y.S. Romen, Bulletin of the Railway Research Institute, 1, 17 (2015)

2. Concept of lubrication development in the wheel/rail system, Russian Railways, 75 (2008)

3. Yu.S. Romen, O.A. Suslov, A.A. Belyaev, Bulletin of the Railway Research Institute, 76(6), 354 (2017)

4. V.O. Pevzner, Bulletin of the Railway Research Institute (Bulletin of VNIIZHT), 79(4), 209 (2020)

5. V.O. Pevzner, A.V. Zamukhovsky, Bulletin of the Railway Research Institute (Bulletin of VNIIZHT), 9, 26 (2019)

6. Research of the track and rolling stock interaction in the USA, World Railways, 9, 45 (1991)

7. S.M. Zakharov, I.A. Zharov, I.A. Komarovsky, Collection of reports of the International Conference of the International Heavy Haul Association "Problems of the wheel and rail interaction", 1, 221 (1999)

8. I.L. Parakhnenko, Analysis of interaction forces in the wheel/rail contact in different frictional options, 2(61), 54 (2019)

9. Utility Patent. No. 2220410 RF B61K 13/00 Tribometer. Puzanov V.A., Dobrynin L.K., Kossov B.C., Panin Yu.A., Khalyavin V.S., Gapchenko V.P., Chizhikov A.P. Priority 25/09/2002. Publ. on 27/12/2003, 36

10. I.L Parakhnenko., S.G. Akkerman, Transport of Ural. Yekaterinburg: UrGUPS, 2(41), 58 (2014)

11. UM. - Elektron. Journal - Computational Mechanics Laboratory (2019) http://www.umlab.ru/

12. Modelling of rail vehicle dynamics/ User Guideline "Universal Mechanism 8" (2016) http://www.umlab.ru/

13. Simon D. Iwnicki, The Manchester benchmarks for rail vehicle simulation (1999)

14. I.L. Parakhnenko, Transport of Ural. Yekaterinburg: UrGUPS, 2(61), 54 (2019) 
15. I.L. Parakhnenko, S.G. Akkerman, Development of infrastructure and logistics technologies in transport systems (Railtrans-2019): Collection of works of the Third International Scientific and Practical Conference. Part 1 Development of transport infrastructure and transportation management. St. Petersburg : FGBOU VO PGUPS, 367 (2020)

16. V. Pevzner, U. Romen, K. Shapetko, Control of energy aspects of track and rolling stock interaction, MATEC Web of Conferences, 239, 01044 (2018) 